\title{
Formation of digital competencies in the public policy sphere: the EU and Russia experience
}

\author{
Svetlana Morozova ${ }^{1, *}$, and Alexander Kurochkin ${ }^{1}$ \\ ${ }^{1}$ St. Petersburg University, Faculty of Political Science, Smolny St., 1/3, 191124 St. Petersburg, Russia
}

\begin{abstract}
Research background: Today information technologies occupy many spheres of human activity, including political government systems. The new digital reality requires a revision of the political and economic science methodology and a transition to a new paradigm that meets the challenges of information globalization.

Purpose of the article: The article is devoted to the study of the European and Russian experience in teaching digital skills to citizens and civil servants. The need to improve existing digital competencies in the context of widespread digitalization is determined.

Methods: The main research method is a comparative analysis of the European and Russian approaches to the digital competencies formation in the sphere of public administration and politics, emerging and transforming under the influence of widespread globalization and digitalization. Particular attention is paid to state strategies, programs and projects aimed at digital development and modernization of all areas of society.

Findings \& Value added: On the basis of the study, the authors formulated the European and Russian models of teaching digital competencies, focusing on the sphere of public administration and politics, highlighted the disadvantages of the Russian model and the advantages of the European approach, and also offered recommendations on the prospects for the spread of European practice in Russian conditions.
\end{abstract}

Keywords: Globalization; Digitalization; Digital Competencies, ICT

JEL Classification: $O 32 ; O 35 ; O 38$

\footnotetext{
* Corresponding author: s.s.morozova@,spbu.ru
} 


\section{Introduction}

Rapidly evolving technologies transform the traditional ways of the public economy sector functioning. At the same time, they provide governments with an opportunity to ensure effective decision-making processes for sustainable development and improving the citizens'well-being. However, the problem of the prevalence of the information and communication technologies' (ICT) pace development over the speed of governments' response to this challenge remains urgent.

Often, the public sector itself inadvertently creates digital barriers by implementing new technologies (artificial intelligence (AI), blockchain, cloud computing, big data, analytics) and providing e-services to citizens who cannot take full advantage of them. Moreover, digital barriers are associated not so much with a lack of access to ICT infrastructure, but with a lack of social justice in the modern information world. Therefore, to expand access to the Internet, states are making serious efforts (The United Nations E-Government Survey 2018).

In this regard, the professional training of government employees to work with digital government technologies in order to quickly adapt them to the digitalization challenges is of particular importance. It is no longer enough for authorities to provide e-government services to have only basic skills in using ICT, most of them need additional «digital» training in policy modeling, data analysis, project management, electronic interaction with citizens.

Equally important is the digital skills training for all groups of the population: in various sectors of the digital economy, employees with a high level of digital competencies are in demand in order to succeed in the global technology market, and employees, in turn, need digital skills to thrive in an increasingly digital and rapidly changing labor market.

\section{Methods}

The main research questions of this article are: What is the significance of digital competencies for modern society? What ways of digital competencies development are being implemented in Europe and Russia at the state level? What are the challenges these countries face in the implementation of projects aimed at digital transformation in the field of public administration and politics? What conditions are necessary for the effective digital competencies development?

The main research methodology is a comparative analysis of the European and Russian experience in the development of citizens and civil servants digital competencies. The authors analyze in detail government strategies, programs and projects aimed at digital development in all spheres of society, paying special attention to the public administration field. Based on secondary sources of information (studies of the European Commission, Russian State Statistics Service, etc.), the authors identify the level of digital skills development in Europe and Russia. Based on the results of the study, the authors formulate the European and Russian digital skills improvement models for citizens and civil servants.

\section{Results}

The European Union member states a few years ago assessed the need for digital development, both for government employees and citizens. In 2016, the European Commission adopted a «New Skills Agenda for Europe», that was centred on three key work strands:

1. Improving the quality and relevance of skills formation;

2. Making skills and qualifications more visible and comparable;

3. Improving skills intelligence and information for better career choices. 
The year 2020 has become a new stage in the EU digital transformation. The COVID-19 pandemic has become a challenge for the world's Governments, necessitated new digital development in all societal spheres, and increased the role of digital experts and ICT professionals.

In February 2020, the European Commission published a new digital strategy for Europe «Shaping Europe's digital future», focusing on four key objectives that contribute to the development of Europe's own way towards a digital transformation working for the benefit of people through respecting European values:

- Technology that works for people,

- A fair and competitive economy,

- An open, democratic and sustainable society,

- Europe as a global digital player.

According to the new digital strategy, improving education and skills is a key part of the overall vision for digital transformation in Europe. For instance, European companies need digitally savvy employees to excel in the global technology marketplace, employees in turn need digital competencies to thrive in an increasingly digital and rapidly changing labor market. The new strategy emphasizes the need for successful careers in technology, not only for men, but also for women.

Key actions to achieve the goals set in the strategy include, but are not limited to:

- A Digital Education Action Plan to boost digital literacy and competences at all levels of education,

- A reinforced Skills Agenda to strengthen digital skills throughout society and a reinforced youth guarantee to put a strong focus on digital skills in early career transitions.

In addition, the European Commission emphasizes that over $90 \%$ of jobs already require at least basic digital skills, yet $43 \%$ of European citizens and over a third of the EU labor force lack them. The Netherlands and Finland are the frontrunners in the digital skills development in EU, while Bulgaria and Romania are lagging behind.

In March 2021, the Commission presented a vision for Europe's digital transformation by 2030. This Digital Compass for the EU's digital decade includes four cardinal points:

- Skills (20 million ICT specialists + gender convergence; min $80 \%$ of population with basic digital skills)

- Digitalization of public services $(100 \%$ online public services; $100 \%$ of citizens having access to medical records; $80 \%$ citizens using digital ID)

- Digital transformation of businesses

- Secure and sustainable digital infrastructures

The Digital Europe Program (DIGITAL) provides strategic funding to develop a skilled pool of ICT experts with the necessary skills to deliver cutting edge solutions in Europe. It is a new EU funding programme that focused on bringing digital technology to businesses, citizens and public administrations. DIGITAL also supports key EU initiatives and actions in the field of digital skills and jobs, such as the Digital Education Action Plan, the Digital Decade targets, as well as various national actions under the EU Recovery and Resilience Facility.

A significant phase in the digital skills development in Europe was the creation of The Digital Skills and Jobs Coalition (DSJC) and The Digital Skills and Jobs Platform (DSJP). The Digital Skills and Jobs Coalition (DSJC) is an EU initiative bringing together Member States, companies, social partners, non-profit organizations and education providers, who work to address the lack of digital skills in Europe. The Coalition's efforts cover four pillars: Digital skills for all, Digital skills for the labor force, Digital skills for ICT professionals, Digital skills in education.

Thus, the Digital Skills and Jobs Coalition includes: 
- Establishing national digital skills coalitions connecting public authorities, business, education, training and labor market stakeholders,

- Developing concrete measures to bring digital skills and competences to all levels of education and training, supporting teachers and educators and promoting active involvement of business and other organizations.

The Digital Skills and Jobs Platform (DSJP) has been created as one of the initiatives launched under the Connecting Europe Facility Program. It aims to strengthen the digital skills pillar of the program, providing a wide range of high-quality information, resources and opportunities related to the area of digital skills and jobs across all levels, from basic to advanced. Moreover, DSJP contains interactive map that shows key data, insights and actions on digital skills and jobs in each EU Member State.

At the political level, the newest and main initiatives that will drive the digitalisation of the public sector in Europe are the Shaping Europe's Digital Future strategy, the White Paper on Artificial Intelligence, the Strategy for a sustainable and digital Europe, the Action Plan for better implementation and enforcement of single market rules, a new Industrial Strategy for a globally competitive, green and digital Europe, and the European Data Strategy.

As part of the Digital Single Market Strategy for Europe (DSM), a new eGovernment Action Plan for 2016-2020 was launched that aimed to remove existing digital barriers to the Digital Single Market and to prevent further fragmentation arising in the context of the modernization of public administrations. The action plan was defined as follows: «By 2020, public administrations and public institutions in the European Union should be open, efficient and inclusive, providing borderless, personalised, user-friendly, end-to-end digital public services to all citizens and businesses in the EU. Innovative approaches are used to design and deliver better services in line with the needs and demands of citizens and businesses. Public administrations use the opportunities offered by the new digital environment to facilitate their interactions with stakeholders and with each other» (2016-2020). This Action Plan, inter alia, included a part on using digital tools and upskilling the civil servants.

The UN E-Government Survey provides the most comprehensive picture of the digitalization development in the field of public administration. According to the 2020 Survey, despite positive dynamics in the e-government development around the world, many Governments continue to face challenges linked to multiple contextual factors such as: resource limitations; a lack of digital infrastructure; insufficient capacities or capabilities, especially in developing countries and countries in special situations.

Some countries face specific obstacles relating to issues such as: digital inclusion, data privacy, cybersecurity.

The Digital Economy and Society Index (DESI) summarises indicators on Europe's digital performance and tracks the EU countries progress. The International Digital Economy and Society Index (I-DESI) measures the digital economy performance of EU27 Member States and the EU as a whole in comparison with 18 other countries around the world (Australia, Brazil, Canada, Chile, China, Iceland, Israel , Japan, Mexico, New Zealand, Norway, Russia, Serbia, South Korea, Switzerland, Turkey, United Kingdom, and the United States). Following the logic of this study, let us turn to I-DESI in terms of measuring human capital. Table 1 comprised of five indicators grouped together in two sub-dimensions that examine the skills needed to take advantage of the opportunities offered by a digital society. 
Table 1. European actions for skills development.

\begin{tabular}{|c|c|c|}
\hline \multirow{5}{*}{2 Digital Skills } & \multirow{3}{*}{ Internet user skills } & Basic skills \\
\hline & & Above basic skills \\
\hline & & At least basic software skills \\
\hline & \multirow{2}{*}{$\begin{array}{c}\text { Advanced skills and } \\
\text { development }\end{array}$} & Telecommunications FTEs \\
\hline & & ICT graduates \\
\hline
\end{tabular}

Source: Author's own work

According to the International Digital Economy and Society Index (I-DESI), in 2018, the EU27 Member State average performance for the human capital dimension was 41.8. Ten of the 18 non-EU countries had a higher score in 2018. In Russia, this figure was slightly below -37.2 .

In this regard, it should be noted that, in terms of key indicators of ICT use and IT literacy of the population, the differences between the constituent entities of the Russian Federation, urban and rural areas are higher than in Europe, and may exceed the differences between developed and developing countries that are just entering the information age. The indicators of the digital inequality in Russia are more pronounced than in economically developed countries. First of all, this concerns the gap between generations: the level of computer and Internet use by young people in Russia and the EU practically does not differ, but in the older age groups $(55+)$ one can observe more than twofold differences in the proportion of ICT users. The way to overcome the digital divide is to form and implement a digital inclusion policy. State policy in the field of digital inclusion involves increasing IT literacy, developing digital infrastructure, and creating content in accordance with user requests. Skills are a key variable in the digital inclusion policy model (Plotichkina et al., 2020).

The problem of the digital competencies formation for both providers (civil servants) and recipients of services (citizens) is no less acute in Russia than in the European Union. According to the statistics collection of the Higher School of Economics «Indicators of the Digital Economy: 2021», 74.8 percent of the Russian Federation citizens receive state and municipal services in electronic form. At the same time, 16.3 percent of them note a lack of skills and knowledge in the use of ICT.

The digital transformation of the entire public administration system in the Russian Federation is regulated primarily by the federal project «Digital Public Administration», included as one of three applied areas in the state program «Digital Economy».

Experts from the Higher School of Economics noted the following problem areas that are most relevant for ensuring an effective process of digitalization of the system of state and municipal administration in Russia (2019):

- Imbalance in the system of distribution of state powers, the organizational structure of state bodies and interactions among them;

- Ineffectiveness of budgetary expenditures for the maintenance of the state apparatus and performance of functions;

- Insufficient level of labor productivity in the executive authorities, which is compensated by the excessive number of employees;

- Low level of modern digital competencies and professional qualifications of civil servants;

- Lack of commitment in the state apparatus to such values as efficiency, accountability, serving the public interest.

Digital competencies are very heterogeneous and this should be taken into account when we assess the degree of their digital implementation in the public and civil service. Among 
them, at least three main levels can be distinguished. The first one is general skills of using ICT in professional activity. They, as a rule, are associated with working with internal and peripheral computer devices, user skills in composing and processing electronic documents, searching for information on the Internet, skills in working with databases, active use of corporate e-mail. The second level is specialized professional competencies required for the production of IC services and products. Finally, the third level is formed by the so-called «complementary skills that support the performance of new tasks related to the use of ICT in the workplace. In particular, these include the use of social media to communicate with colleagues and customers, brand promotion of products on e-commerce platforms, etc.» (Vasilyeva et al., 2018, p.35).

For most positions in the state and municipal service, the competencies of the first level are sufficient. Such skills are tested during the passage of competitions for the relevant positions and are generally required. However, the challenge lies in improving these skills, as software and digital resources are constantly being updated and new products are emerging. All this requires regular retraining and additional professional training. This problem is not yet solved so effectively. Despite the fact that, according to the Russian Federal State Statistics Service (Rosstat), in 2019, 178,726 civil servants received additional professional education, of which 114,104 were civil servants of federal ministries and departments and 64,622 civil servants of the constituent entities of the Russian Federation, established by Decree of the Government of the Russian Federation dated May 6, 2008 No. $362 «$ On approval of state requirements to professional retraining and advanced training of civil servants of the Russian Federation», the procedure and terms of retraining and advanced training do not allow ensuring its proper dynamism in all positions groups.

Positive examples are of a point nature and cover only a small proportion of public servants. So, for example, in 2018, within the framework of the national strategic initiative Chief Data Officer (CDO) - the Program for training leaders in government in data-driven governance, 200 civil servants from 38 regions, representatives of the Ministry of Digital Development of Russia and state corporations passed the first training module. Students of the program have mastered the latest technologies for collecting, analyzing, using and protecting data (Vasilyeva et al., 2018).

Another pressing problem is the lack of uniform templates for formalizing requirements for professional knowledge and skills in the field of information and communication technologies for civil service positions: in some official regulations they are referred to «professional skills», in others - to «basic knowledge and skills» etc.

The second and third levels of competencies are represented in the civil service and in the public sector as a whole, significantly weaker than in other professional areas. According to Rosstat, the number of IT specialists among civil servants in 2017-2018 is no more than $2 \%$, while, for example, in the banking sector, on average, about $10 \%$ (from 8 to $12 \%$ ) of all employees. The reasons for this situation lie primarily in the uncompetitive working conditions in the public sector, in comparison with the overwhelming majority of private sectors, as well as weak incentives from the heads of state and municipal authorities to change the professional structure of positions, expand the staff of specialized units responsible for the digitalization of state and municipal governance processes. At the same time the number of graduated specialists in the field of ICT is more than sufficient. So, according to the Ministry of Education and Science, the number of budget-funded bachelor's degree places in the specialties: «Informatics and Computer Engineering», "Computer and Information Sciences», «Information Security» amounted to at least $11 \%$ of the total number of budgetfunded places in the 2019-2020 academic year.

According to the state program «Digital Economy of the Russian Federation», by 2024 the number of graduates of university IT programs should grow at least 2.5 times - up to 120 thousand people a year, and the number of graduates with IT competencies at an average 
level - up to 800 thousand. In 2018, the Far Eastern Federal University opened the first School of Digital Economy in Russia with master's programs in cybersecurity, big data, artificial intelligence, virtual reality, etc.

Summarizing the study, we will formulate the European and Russian digital skills improvement models for citizens and civil servants.

European model includes the following components:

- Support in choosing, obtaining and improving qualifications, including in the field of digital technologies;

- Regional, national and sectoral cooperation in education, employment and industry to improve digital skills among the general population;

- Vocational education and training modernization;

- Special digital competencies development;

- Standardization of information on qualifications and professional experience;

- A toolkit for identifying digital skills in migrants;

- Targeted services for vulnerable populations in the use of ICTs in order to increase digital literacy and overcome digital barriers;

- Digital competitiveness comprehensive monitoring system;

- Providing a wide range of high-quality information, resources and opportunities related to the area of digital skills and jobs across all levels;

- Intersectoral collaboration bringing together Member States, companies, social partners, non-profit organizations and education providers to address the lack of digital skills in Europe.

The Russian model contains the following characteristics:

- Providing opportunities for obtaining basic digital education and increasing the level of digital competencies through the launch of specialized educational programs;

- Lack of a standardized approach to formulating digital competencies;

- Lack of uniform templates for formalizing requirements for professional knowledge and skills in the field of information and communication technologies for public civil service positions;

- Uncompetitive working environment in the public sector, compared to the vast majority of private sector;

- Weak incentives on the part of the heads of state and municipal authorities to change the professional structure of positions, expand the staff of specialized units responsible for the digitalization of state and municipal governance processes;

- Weak level of cross-sectoral and cross-regional interaction in the digital competencies development;

- Lack of high quality and systematized information, resources and opportunities related to the area of digital skills.

\section{Discussions}

The topic of digital transformations in the face of new global challenges and risks is extremely relevant today. The range of issues discussed and covered in the scientific literature is very wide: formation of digital culture (Moravcikova, 2018), development of digital education (Corejova et al., 2020), transformation of the digital economy and business (Zaychenko et al., 2020), modernization of the public administration system (Ziyadin et al., 2020), etc.

In the scientific literature, studies on the impact of the COVID-19 pandemic on the digitalization development have acquired particular relevance today. Lanshina et al. (2020), 
for instance, conducted a content analysis of over 20 policy proposals for coping with the COVID-19 crisis that have been published by influential international organizations, governments, corporations, academics and civil society groups and proposed long-term measures aimed at restoring the global economy and moving toward more equitable and sustainable development.

Research on digital skills in the context of the COVID-19 pandemic deserves special attention. Thus, Beaunoyer et al. (2020) investigated how COVID-19 can potentiate digital inequalities, and how digital inequalities potentiate vulnerability to COVID-19.

In general, the problem of digital competencies development is not very common in scientific research and is considered mainly through the prism of the digital socialization or digital inclusion phenomenon. In this vein, Plotichkina et al. (2020) clarify that the modern understanding of digital inequality is associated not so much with the problem of Internet access, but with the ability of users to use digital technologies to improve their lives. Soshynska (2020) presented an overview of European Union policy regarding digital inclusion and digital transformation and described the impact of the digital skills to rising digital inclusion level. Special attention in their work is paid to the analysis of different types of digital skills within geographical groups of countries: Western Europe, Northern Europe, Southern Europe, and Eastern Europe. The results of the analysis reveal that Nordic countries demonstrate the highest level digital skills, followed by the Western and Southern countries, and Eastern European countries have much lower rates.

An interesting study was carried out by Van Laar et al. (2019), identifying how various skills relate to each other. Through a survey of a sample of 1,222 professionals working in the creative industries, they tested, by using path analysis, whether six 21 st-century digital skills have a sequential and conditional nature. «The sequence of the model starts with information and communication digital skills, followed by collaboration, critical thinking, and creative digital skills. All skills lead to problem-solving digital skills. The results confirm that the analyzed skills build on each other sequentially» (Van Laar et al., 2019, p.3462).

Level study of digital skills among migrants is fairly common. Stiller and Trkulja (2018), for example, conducted a lab experiment designing tasks with varying difficulty to position the digital competencies of refugee migrants on the digital skill scale.

In scientific research the digital competencies formation analysis in the political sphere is most often encountered. Such work is usually aimed at solving specific problems. For instance, Bastien et al. (2020) analyzed the role of online technologies and digital skills in the political participation of citizens with disabilities. Jaculjakova et al. (2020) emphasize the need to develop digital skills of citizens in order to live a comfortable life in the context of constantly evolving digitalization, as well as the need to promote digital skills in primary, secondary schools, various computer courses, in the implementation of training in individual jobs, etc.

Fedorova et al. (2019) revealed problems of leaders training in public governance and administration in digital economics.

Krpalek et al. (2021) identify the requirements for competences necessary for the effective performance of job positions in public administration in the Czech Republic, including the mapping of interest in further training. 


\section{Conclusion}

To conclude, it should be noted that Europe is characterized by a systematic approach to the digital skills development. The new digital development strategy clearly formulated the need to develop digital competencies among different groups of citizens through the implementation of a number of actions initiated by the government and implemented on the basis of regional, national and intersectoral collaborations.

The Russian Federation, in comparison with the European experience, is at the initial stage of implementing large-scale initiatives in the field of digital competencies. So, in 2020 - 2021, the University 2035 began operating - the first network university of a new type in Russia, which combines research and educational organizations, as well as an IT companies.

(CDO) and digital economy teams training programs, carried out on the basis of the University 2035, are being implemented within the framework of the federal project «Staff for the Digital Economy» of the «Digital Economy of the Russian Federation» national program. Its goal is to increase the efficiency of enterprises and organizations in priority sectors of the economy, as well as the authorities of the Russian Federation through the technologies and management practices introduction based on data.

In addition, in 2019 the Digital Professions platform was launched. This state project is aimed at solving the priority tasks of the state in the field of staff training for the digital economy:

- Promotes the development of human resources in the interests of industries, regions, companies and organizations;

- Provides professional development and employment of citizens in the IT sector and digital professions.

- Gives impulse to the additional education system development in the digital economy.

In 2021, the project of personal digital certificates is planned to be reformatted into a wider format of training for additional education programs in order to develop the competencies of the digital economy among various groups of citizens.

The studied European and Russian experience allows us to conclude that a necessary condition for the effective digital competencies development is a systemic transformation of management processes, digital culture and a radical restructuring of public administration.

The era of widespread digitalization imposes special requirements on government bodies that should be able to work in the new environment, and on citizens who must have the necessary skills to work with digital technologies. Therefore, it is necessary to teach these skills in secondary and higher schools, as well as to raise the level of existing digital competencies, including among civil servants. In this vein, the European practice is rightfully considered one of the most successful in the world.

\section{Acknowledgements}

The research and publication are funded by the Grants Council of the President of the Russian Federation (Grant №MK-3016.2021.2, Dynamic model formation for optimizing e-government in the Russian Federation in the case of new challenges and risks) and the Russian Foundation for Basic Research (Alexander Kurochkin) (project № 21-011-31356, City government and self-government systems transformations study in the context of the constitutional institutionalization of the public authority unified system in the Russian Federation).

\section{References}

1. Bastien, F., Koop, R., Small, T. A., \& Giasson, T. (2020). The role of online 
technologies and digital skills in the political participation of citizens with disabilities. Journal of Information technology \& politics, 17(3), 218-231.

2. Beaunoyer, E., Dupere, S., \& Guitton, M. J. COVID-19 and digital inequalities: Reciprocal impacts and mitigation strategies. Computers in human behavior, 111, 106424.

3. Corejova, T., Chinoracky, R., \& Valicova, A. (2020). University processes and digital transformation. INTED Proceedings, 1873-1877.

4. Krpalek, P., Berkova, K., Kubisova, A., Krpalkova Krelova, K., Frendlovska, D., \& Spiesova, D. (2021). Formation of Professional Competences and Soft Skills of Public Administration Employees for Sustainable Professional Development. Sustainability, 13(10), 5533.

5. Fedorova, Y., Babenko, K., Malykhina, Y., Yarmosh, O., \& Malykhina, V. (2019). Problems of leaders training in public governance and administration in digital economics. Financial and credit activity-problems of theory and practice, 3(30), 501509.

6. Jaculjakova, S., \& Stofkova, K. R. (2020). Analysis of basic digital skills of citizens in selected region. Proceedings INTED, 6141-6149.

7. Krpalek, P., Berkova, K., Kubisova, A., Krpalkova Krelova, K., Frendlovska, D., \& Spiesova, D. (2021). Formation of Professional Competences and Soft Skills of Public Administration Employees for Sustainable Professional Development. Sustainability, 13(10), 5533.

8. Lanshina, T., Barinova, V., Kondratyev, A., \& Romantsov, M. (2020). Sustainable development and digitalization: the unusual COVID-19 crisis requires original solutions. International organisations research journal, 15(4), 91-114.

9. Moravcikova, V. (2018). Digital culture and issues of production and reception of digital media. Marketing identity, 420-429.

10. Plotichkina, N., Morozova, E., \& Miroshnichenko, I. (2020). Digital technologies: the policy of expanding accessibility and development of skills of use in Europe and Russia. World Economy and International Relations, 64(4), 70-83.

11. Soshynska, Y., \& Soshynska, V. (2020). Digital Skills of European Citizens: To Be on Time. In K. S. Soliman (Eds.), Proceedings of the 35th International-BusinessInformation-Management-Association Conference (IBIMA), 16654-16661.

12. Stiller, J., \& Trkulja, V. (2018). Assessing Digital Skills of Refugee Migrants During Job Orientation in Germany. Lecture Notes in Computer Science, 10766, 527-536.

13. Van Laar, E., Van Deursen, A. J. A. M.,Van Dijk, J. A. G. M., \& De Haan, J. (2019). The Sequential and Conditional Nature of 21st-Century Digital Skills. International journal of communication, 13, 3462-3487.

14. Vasilyeva, E. V., Pulyaeva, V. N., \& Yudina, V. A. (2018). Development of digital competencies of government civil servants of the Russian Federation. Business Informatics, 4(46), 28-42.

15. Zaychenko, I., Gorshechnikova, P., Dubgorn, A., \& Levina, A. (2020). Digital transformation of business: approaches and definitions. In K. S. Soliman (Eds.), Proceedings of the 35th International-Business-Information-Management-Association Conference (IBIMA), 18728-18737.

16. Ziyadin, S., Malayev, K., Fernández-Plazaola, I., Ismail G., \& Beyzhanova, A. (2020). Digital modernization of the system of publicadministration: prerogatives and barriers. E3S Web of Conferences, 159, 05003,1-11. 